\title{
Dynamic Young's Modulus and Dimensional Stability of Batai Tropical Wood Impregnated with Polyvinyl Alcohol
}

\author{
M. S. Islam ${ }^{1}$, S. Hamdan ${ }^{1}$, M. R. Rahman ${ }^{1 *}$, I. Jusoh ${ }^{2}$, and N. F. Ibrahim² \\ ${ }^{1}$ Faculty of Engineering, Universiti Malaysia Sarawak, Malaysia \\ ${ }^{2}$ Faculty of Science, Universiti Malaysia Sarawak, Malaysia \\ Received 25 June 2009, accepted in final revised form 20 February 2010
}

\begin{abstract}
Batai tropical wood (paraserianthes moluccana) was impregnated with three levels of poly vinyl alcohol (PVA) solutions $(25 \%, 50 \%$ and $75 \%)$ and the dynamic Young's modulus, water absorption and dimensional stability of the manufactured wood polymer composites (WPC) were assessed. The modified wood polymer composites (WPC) were characterized by microstructural analysis (Fourier transform infrared spectroscopy and scanning electron microscopy) and free-free vibration testing. The dynamic Young's modulus $\left(E_{\mathrm{d}}\right)$ was calculated using the free-free flexural vibration method. Fourier transform infrared spectroscopy indicated the absorption bands of raw wood to be $1627 \mathrm{~cm}^{-1}$ due to carbonyl stretching and WPC show increased absorption band near $1733 \mathrm{~cm}^{-1}$. WPC of $75 \%$ PVA solution exhibited improved dimensional stability and lower water absorption. The manufactured WPC yielded a higher Young's modulus compared with the raw one.
\end{abstract}

Keywords: Wood polymer composite; Tropical wood; Non-destructive testing.

(C) 2010 JSR Publications. ISSN: 2070-0237 (Print); 2070-0245 (Online). All rights reserved.

DOI: $10.3329 /$ jsr.v2i2.2729 J. Sci. Res. 2 (2), 227-236 (2010)

\section{Introduction}

Wood is a three-dimensional polymeric material, made up mainly of cellulose, hemicellulose and lignin. These three polymers constitute the cell wall and are responsible for the physical and chemical properties exhibited by the wood. All of these polymers have accessible hydroxyl groups. Wood attracts moisture through hydrogen bonding, making it dimensionally unstable. The dimensional stability and mechanical properties of wood can be improved by using impregnation techniques with suitable chemicals that can react with cell wall components [1].

The physical and mechanical properties of wood may also be improved by preparing composites with different monomers. The polymer component of the wood polymer composite (WPC) simply fills up the capillaries, vessels and other void spaces within the wood structure. WPC may be one of the most dynamic sectors of today's plastic industry.

\footnotetext{
*Corresponding author: reza_bawas@yahoo.com
} 
Fabricated WPC generally exhibits effective dimensional stability and excellent mechanical properties [2-3]. Recently, wood has been impregnated with a variety of monomers such as styrene, epoxy resins, urethane, phenol formaldehyde, methyl methacrylate (MMA), vinyl or acrylic monomers to change its dimensional and mechanical properties [4]. WPC as a structural material has been utilized in marine applications, including fender systems used to protect docking structures and vessels during vessel berthing [5].

In 1958, the free-free flexural vibration method was introduced by Haermon [6] to investigate the dynamic Young's modulus $\left(E_{\mathrm{d}}\right)$ of wood [6]. Previous studies showed a good relationship between the $E_{\mathrm{d}}$ and static Young's modulus $\left(E_{\mathrm{s}}\right)$ obtained from quasistatic tests [7, 8]. Young's modulus from vibration was consistently larger than those obtained from quasi-static test. The different value is to be expected, considering the rheological characteristics of wood and the shorter time of load duration occurring during vibration [7]. For vibrating samples, the elastic restoring force is proportional to displacement and the dissipative force is proportional to the velocity of sound. Therefore, when a force is applied for a very short duration, the behaviour is like an elastic solid while for longer duration, the behaviour is like a viscous liquid.

This behaviour is more prominent in long duration static bending tests compared to flexural vibration tests [8]. Many studies have been carried out on physical and mechanical properties of wood and WPC [9-13]. Little work, however, has been devoted to tropical wood species [14]. In the present work, Batai (Paraserianthes moluccana) tropical wood species was utilized as starting material keeping in mind that they are easily obtainable as waste products and have a minimal effect on the environment due to their biodegradable properties [9].

However, a major drawback of using this species is its high moisture uptake, biodegradation, and dimensional change with environmental variations which limit its use $[15,16]$. These defects have primarily been ascribed to the presence of hydrophilic hydroxyl groups in the three major wood components (cellulose, hemicellulose, and lignin) and its various cavities. The hydrophilic nature, responsible for moisture absorptions caused swelling and deformation of the product. The dimensional changes of wood can be minimized by suitable chemical impregnation such as the formation of wood polymer composites (WPC), which is a promising way to improve wood properties [17, 18]. In order to overcome this problem, wood species were impregnated with polyvinyl alcohol monomer. Thus the aim of this study is to manufacture composite materials from raw wood using different percentages of monomer solutions for impregnation and to improve the physical and mechanical properties.

\section{Materials and Methods}

Batai (Paraserianthes moluccana) tropical wood species was chosen for this study. The monomer polyvinyl alcohol (PVA) was used to polymerize wood species. polyvinyl alcohol (Merck, Germany) was purchased from Komita (M) Sdn. Bhd. Penang, Malaysia. 


\subsection{Specimen preparation}

Batai wood (Paraserianthes moluccana) was felled and cut into three bolts of $1.2 \mathrm{~m}$ length. Each bolt was quarter sawn to produce planks of $4 \mathrm{~cm}$ thickness and subsequently conditioned to air-dry in a room with relative humidity of $60 \%$ and ambient temperature of around $25^{\circ} \mathrm{C}$ for one month prior to testing. The planks were ripped and machined to $340 \mathrm{~mm}(\mathrm{~L})$ x $20 \mathrm{~mm}(\mathrm{~T}) \times 10 \mathrm{~mm}(\mathrm{R})$ and $60 \mathrm{~mm}(\mathrm{~L})$ x $20 \mathrm{~mm}(\mathrm{R})$ x $20 \mathrm{~mm}(\mathrm{~T})$ specimens for the free-free vibration test and the dimensional stability analysis respectively.

\subsection{Impregnation of wood with PVA}

All oven dried samples were placed in an impregnation vacuum chamber and were evacuated with vacuum pressure of $75 \mathrm{~mm} \mathrm{Hg}$ and held for $10 \mathrm{~min}$. The respective monomer system was introduced into the chamber as the vacuum pressure was released. The samples were kept immersed in the monomer solution for $6 \mathrm{~h}$ at ambient temperature and atmospheric pressure to obtain further impregnation. Samples were then removed from the chamber and wiped clean of excess impregnate. Samples were wrapped with aluminum foil and placed in an oven for $24 \mathrm{~h}$ at $105^{\circ} \mathrm{C}$ for polymerization to take place. The weight percentage gains (WPG \%) were $19 \%, 25 \%$, and $36 \%$ for $25 \%$ PVA solution, $50 \%$ PVA solution and 75\% PVA solution impregnated wood, respectively.

\subsection{Microstructural analysis}

\section{Fourier transform infrared spectroscopy (FTIR)}

The infrared spectra of the raw and treated wood specimens were recorded on a Shimadzu Fourier Transform Infrared Spectroscopy (FTIR) 81001 Spectrophotometer. The transmittance range of scan was 370 to $4000 \mathrm{~cm}^{-1}$. The obtained spectra are described in results and discussions

\section{Scanning electron microscopy (SEM)}

The interfacial bondings between the cell wall polymer and polyvinyl alcohol were examined using a Scanning Electron Microscope (JSM-6701F) supplied by JEOL Company Limited, Japan. The specimens were first fixed with Karnovsky's fixative and then taken through a graded alcohol dehydration series. Once dehydrated, the specimens were coated with thin layer of gold before being viewed on the SEM. The micrographs, taken at a magnification of $150 \times$, are presented in the results and discussions section.

\subsection{Dynamic Young's modulus measurement}

Free-free vibration testing

Determination of $E_{\mathrm{d}}$ was carried out using the free-free flexural vibration testing system as shown in Fig. 1. The specimen was held with AA thread according to the first mode of vibration. 
The specimen with an iron plate bonded at one end was set facing the electromagnet driver and a microphone was placed at the centre below the specimen.

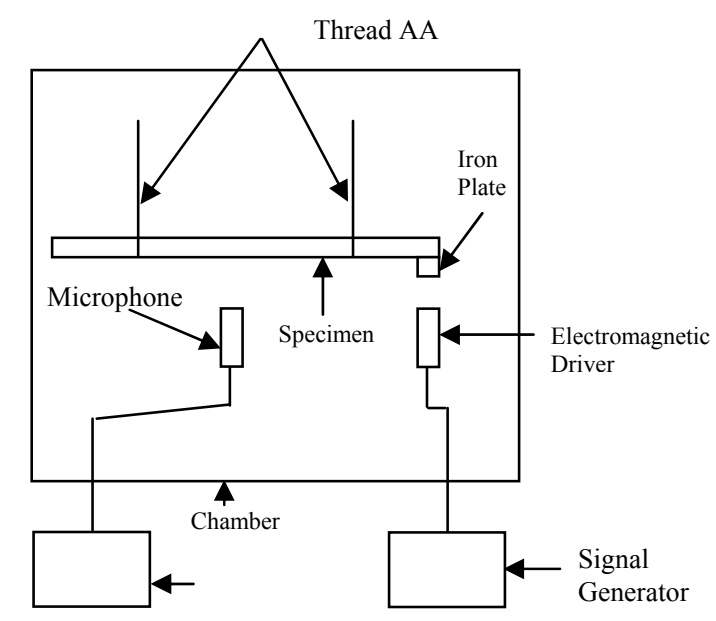

Fig. 1. Schematic diagram of free-free flexural vibration testing machine.

The frequency was varied in order to achieve a resonant or natural frequency. $E_{\mathrm{d}}$ was calculated from the resonant frequency by using the following equation [14].

$$
E_{\mathrm{d}}=4 \pi^{2} \mathrm{f}^{2} l^{4} A \rho / I\left(m_{\mathrm{n}}\right)^{4}
$$

where $I=b d^{3} / 12, d$ is beam depth, $b$ is beam width, $l$ is beam length, $f$ is natural frequency of the specimen, $\rho$ is density, $A$ is the cross sectional area, $n$ is mode of vibration, and $m_{1}=$ 4.730 .

\subsection{Estimation of dimensional stability}

Dimensional stability and water absorption tests were conducted by soaking the oven dried specimens in a water bath at room temperature for $24 \mathrm{~h}$ for each cycle for 7 days. The weight and dimension of the specimens were measured before and after soaking. The water absorption and volumetric swelling coefficient $(S)$ were calculated as follows:

$$
\text { Water absorption }(\%)=\left[\left(W_{2}-W_{1}\right) / W_{1}\right] \times 100 \%
$$

where $W_{2}$ is the specimen weight after soaking and $W_{1}$ is the weight of sample before soaking. The volumetric swelling coefficient $(S)$ is calculated as follows: 
Volumetric swelling coefficient $(S)=\left[\left(V_{2}-V_{1}\right) / V_{1}\right] \times 100 \%$

where $V_{2}$ is the volume of wood after soaking and $V_{1}$ is the volume of wood before soaking in water.

\section{Results and Discussion}

\subsection{Microstructural analysis}

\section{Fourier transform infrared spectroscopy (FT-IR)}

Raw wood specimens were impregnated with polyvinyl alcohol to convert them into WPC. The monomer was successfully impregnated inside wood cell lumen and reduces its hydrophilicity. This is confirmed by the FTIR spectroscopic analysis of the raw wood and WPC as shown in Fig. 2.

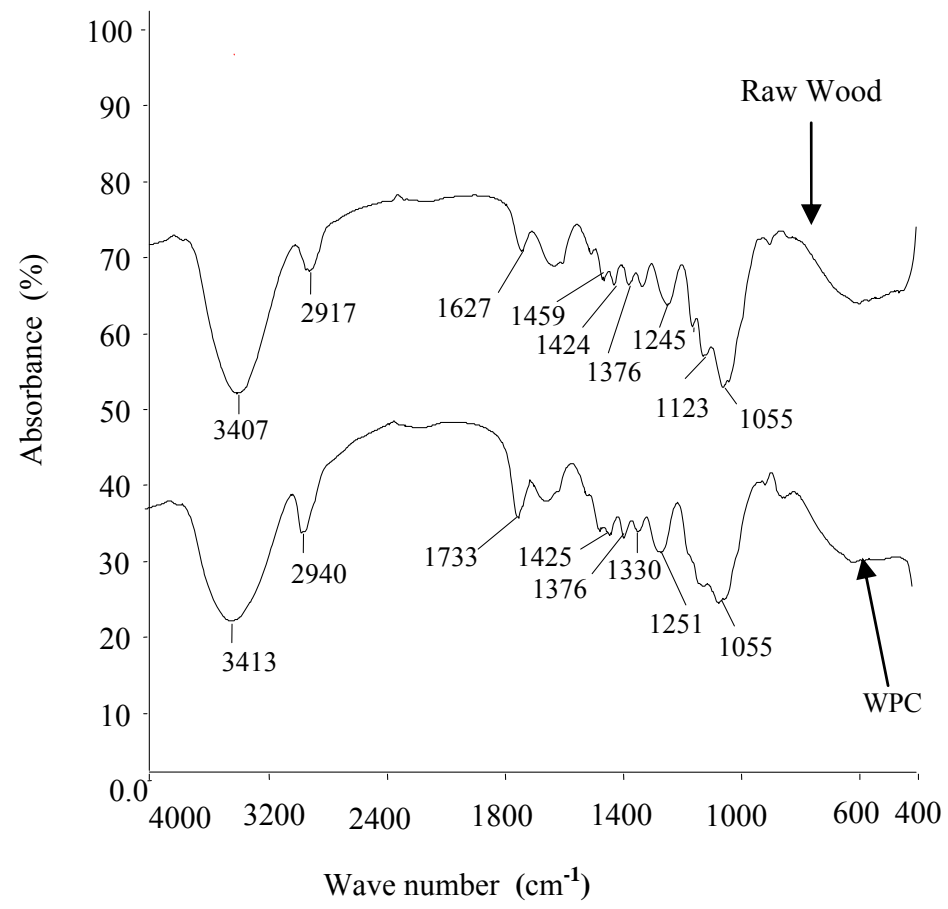

Fig. 2. FTIR of raw wood and wood polymer composites.

The IR spectrum of the treated wood clearly shows the characteristics band in the region of $1733 \mathrm{~cm}^{-1}$ and $2940 \mathrm{~cm}^{-1}$ due to carbonyl stretching and C-H stretching. The IR spectrum of the raw wood shows the absorption band at the region near $1627 \mathrm{~cm}^{-1}$. This 
absorption band is due to carbonyl group of acetyl ester in hemicellulose and carbonyl aldehyde in lignin [19]. However, there is also an increased absorption band near 1733 $\mathrm{cm}^{-1}$. This increased absorption band may be due to the impregnation of PVA monomer inside the cell wall void spaces of wood and converted WPC as shown in Fig. 2.

\section{Scanning electron microscopy (SEM)}

SEM micrographs of raw wood and wood polymer composites from $25 \%, 50 \%$ and $75 \%$ PVA solutions are shown in Fig. 3. The SEM micrographs in Fig.(3a) show that the raw wood fibres' surfaces are covered with an uneven layer, which is probably waxy substances and a number of void spaces, as reported previously [20]. The smooth surface of WPC after impregnation could be explained by the removable nature of the waxy substances on the surface of lignocellulosic materials $[20,21]$ and the ability to fill the void surfaces by the PVA monomer.
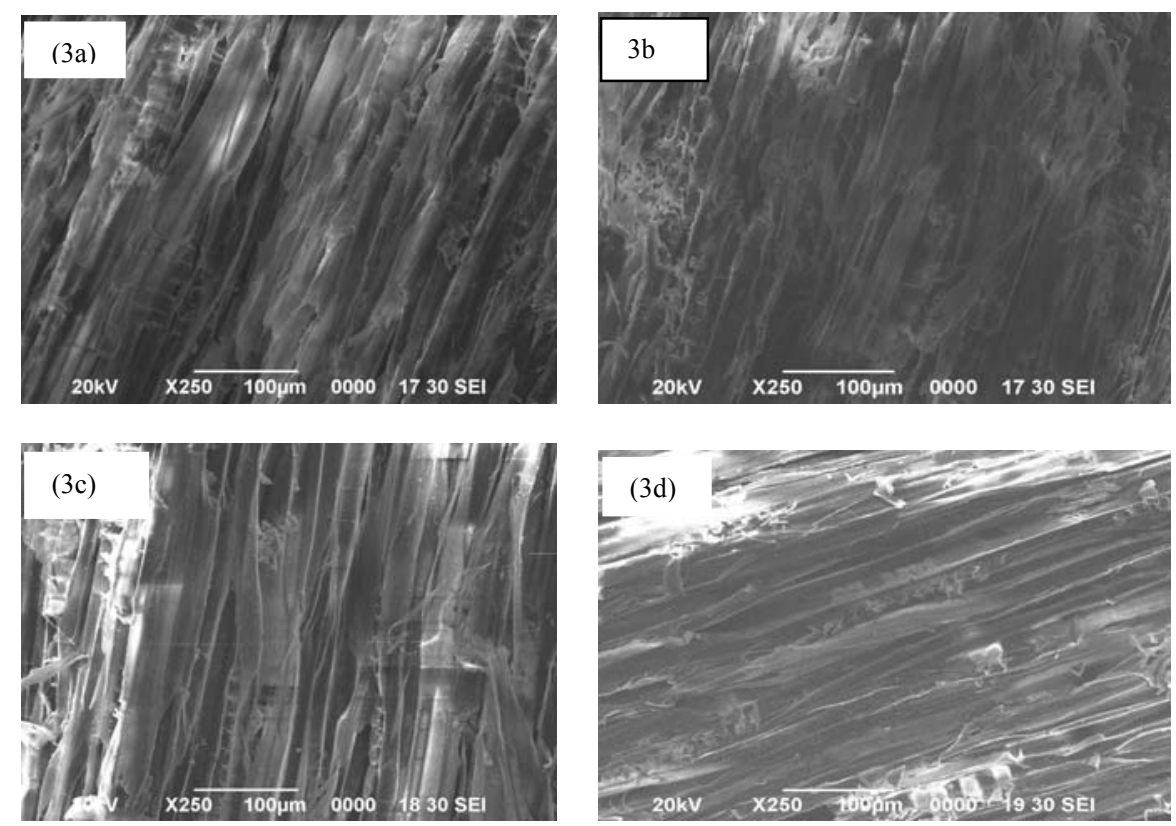

Fig. 3. SEM micrographs of (a) Raw wood, (b) WPC(25\% pva solution), (c)WPC(50\% pva solution) and (d) WPC(75\% pva solution).

The modified wood polymer composite samples (Figs. 3b, 3c, and 3d) clearly show good penetration and adhesion of PVA monomer to the cell wall. Of the three monomer systems used, the 75\% PVA solution loaded (Fig. 3d) WPC samples show the highest impregnation compared to the $25 \%$ and $50 \%$ PVA solution systems. 


\subsection{Dynamic Young's modulus measurement}

Free-free vibration testing

The $E_{\mathrm{d}}$ of $75 \%$ PVA solution loaded WPC were highest followed by $50 \%, 25 \%$ and raw wood as shown in Fig. 4. 75\% PVA solution impregnated WPC yielded higher modulus compared to those of 50 and $25 \%$ impregnated and raw wood species due to the percentage of monomer impregnation, which is in agreement with other researchers [22, 23]. From Fig. 4 it is obvious that WPC of higher monomer loading display the highest modulus and this indicates that more PVA impregnation is also effective for paraserianthes moluccana tropical wood species.

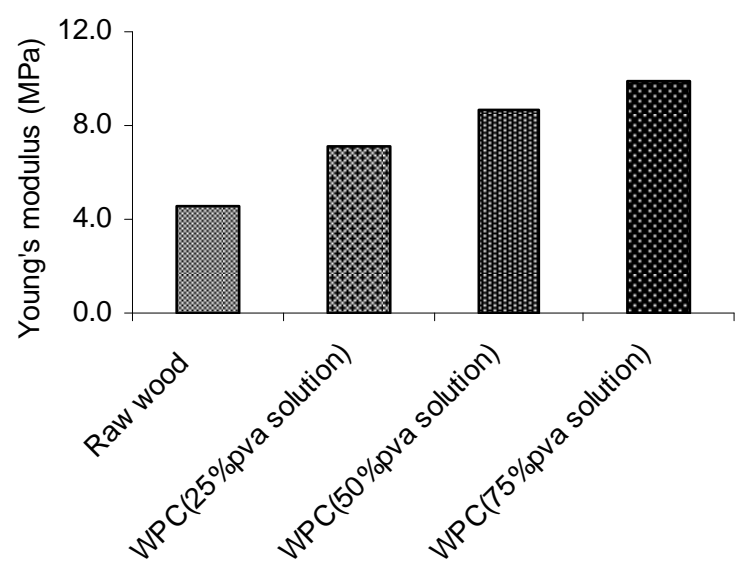

Fig. 4. Young's modulus of raw wood and wood polymer composite.

During monomer loading, all void spaces inside the wood cell wall were filled by the monomer. It is clear that good penetration of the PVA monomer to the cell wall was observed for the 75\% PVA solution impregnated WPC.

\subsection{Water absorption and dimensional stability}

Figs. 5 and 6 demonstrate the results of the water absorption and dimensional stability tests. Fig. 5 shows that the raw wood specimens exhibit a higher percentage of water absorption than the modified wood. This is expected because cell walls with hydrophilic hydroxyl groups will absorb water to their surfaces through the formation of hydrogen bonding $[24,25]$.

From the results, it can be seen that those with 75\% PVA solution impregnated WPC display the lowest absorption. This is expected since 75\% PVA solution has the ability to fill all void lumen inside the wood for polymerization and make it less hydrophilic in 
nature. On the other hand, 50\% and 25\% PVA solution impregnated WPC has the ability to partially fill the lumen to form polymerization.

Fig. 6 indicates that the volumetric swelling coefficient of the raw wood specimen is higher than those of $25 \%, 50 \%$ and $75 \%$ PVA solution penetrated WPC. After modification, the volumetric swelling coefficient of monomer loaded WPC was reduced significantly. Many researchers have observed the same result [13]. The value of the volumetric swelling coefficient decreased with the monomer loading. This is attributed to the bulking of cell walls and reduction in hydrophilicity of the wood after monomer impregnation. This indicates that the dimensional stability of wood is greatly improved by impregnation with PVA monomer and its percentage gain.

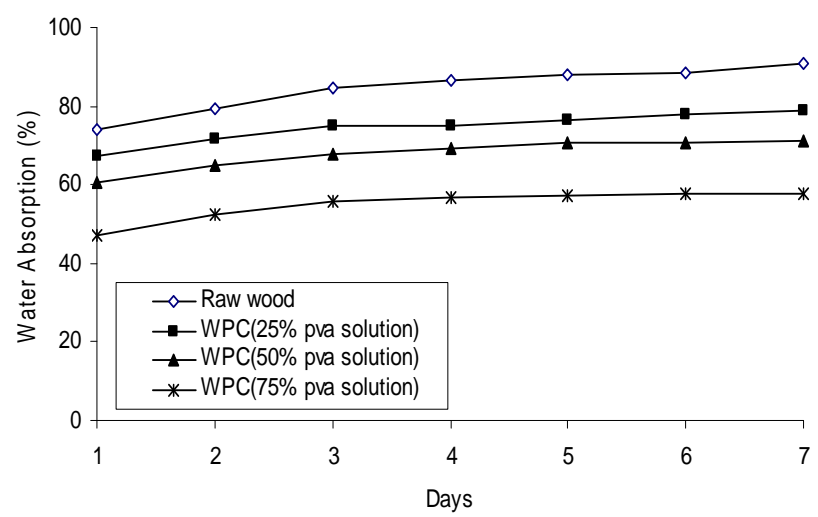

Fig. 5. Water absorption (\%) of raw wood and wood polymer composites.

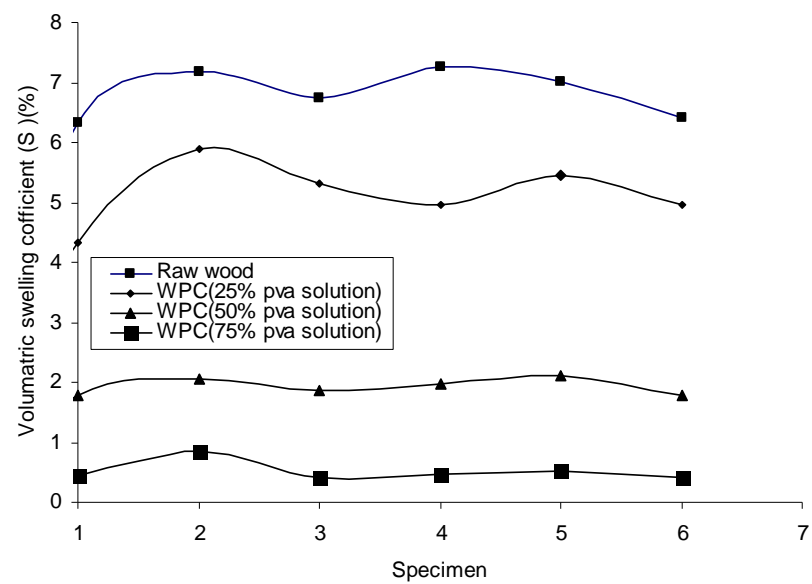

Fig. 6. Volumetric swelling coefficient $(S)$ of raw wood and WPC. 


\section{Conclusion}

In the present paper, the dynamic Young's modulus $\left(E_{\mathrm{d}}\right)$ of $75 \%$ PVA solution loaded WPC was higher than those of 50\% PVA, 25\% PVA solution loaded and raw wood, respectively. For the $75 \%$ PVA solution impregnated WPC samples, lower water absorption and improved dimensional stability are observed. The scanning electron microscopy of WPC shows a smoother surface texture compared to the raw ones. The $75 \%$ PVA solution loaded Batai wood (Paraserianthes moluccana) composites are seen to have the optimum set of mechanical and physical properties in comparison with other fabricated monomer systems.

\section{Acknowledgement}

This work was supported by the Malaysian Government Research Grant FRGS/02(05)655/2007 (20) with the support from the Department of Chemistry, University Malaysia Sarawak.

\section{References}

1. W. C. Feist, R. M. Rowell, and W. D. Ellis, Wood Fib. Sci. 23, 128 (1991).

2. L. L. Mathias, S. Lee, J. R. Wright, and S. C. Warren, J. Appl. Poly. Sci. 42, 55 (1991). doi:10.1002/app.1991.070420107

3. H. L. Chia, V. S. L. lim, L.-T. Ng, N. I. Chem. 20, 181 (1992).

4. R. J. Holyle, and F. E. Woeste, Wood tech. in the design of struct. $5^{\text {th }}$ Edition (Iowa State University Press, USA, 1989).

5. U. C. Yildiz, S. Yildiz, and D. D. Gezer, Bioresource Tech. 96, 1003 (2005). doi:10.1016/j.biortech.2004.09.010

6. R. F. S Hearmon, British Journal of Applied Physics 9, 381 (1954). doi:10.1088/0508-3443/9/10/301

7. J. Bodig and B. A. Jayne, Mechanics of wood and wood composite (Van Nostrand Reinhold Company, New York, 1982).

8. U. B. Halabe, G.M. Bidigalu, H.V.S. Ganga Rao, and R. Ross, Mat. Evaluation. 55 (9), 1013 (1995).

9. C. A. S. Hill, In wood modification chemical, thermal and other processes (John Wiley \& Sons, England, 2006) pp 175-190. doi:10.1002/0470021748.ch8

10. R. M. Rowell, Wood Mat. Sci. and Eng. 1, 29 (2006).

11. K. K. Pandey, Jayashree, and H. C. Nagaveni, Bio Resources 4 (1), 257 (2009).

12. C. Birkinshaw, M. Buggy, and A. Carew, J. Mat. Sci. 24, 359 (1989). doi:10.1007/BF00660981

13. M. Matsunaga, M. Sugiyama, K. Minato, and M. Norimoto, Holzforschung 50 (6), 511 (1996). doi:10.1515/hfsg.1996.50.6.511

14. S. Hamdan, Y. Sedik, I. Jusoh, M. Hasan, and Z.A. Talib, Mat. Sci. and Tech. 25 (6), 805 (2009). doi:10.1179/174328408X339233

15. S. Kumer, Wood Fib. Sci. 26 (2), 270 (1994).

16. A. S. Galperin, G. G. Kuleshov, V. I. Tarashkevich, and G. M. Shutov, Manufacturing and properties of modified wood: A Review of 25 Years Work, Holzforschung 49 (1), 45 (1995). doi:10.1515/hfsg. 1995.49.1.45

17. I. D. Hartley and M. H. Schxeider, Wood Poly. Comp. 27, 421 (1993).

18. R. M. Rowell, Chemical modification of wood, Forest Products Abst. 6 (12), 363 (1983).

19. H. Ismail, M. Edyhan, and B. Wirjosentono, Poly. Test 21 (2), 139 (2002). 
doi:10.1016/S0142-9418(01)00060-5

20. N. E. Zafeiropoulos, D. R. Williams, C. A. Baillie, and F. L. Matthews, Comp. A 33 (8), 1083 (2002). doi:10.1016/S1359-835X(02)00082-9

21. M. S. Sreekala, M. G. Kumaran, and S. Thomas, Mat. Lett. 50 (4), 263 (2001). doi:10.1016/S0167-577X(01)00237-3

22. S. J. Kowalaski, L. Kyzoil, and A. Rybicki, Comp. B 77, 77 (2002). doi:10.1016/S1359-8368(01)00059-2

23. M. Bengtsson, N. M. Stark, and K. Oksman, Comp. Sci. Tech. 67, 2728 (2007). doi:10.1016/j.compscitech.2007.02.006

24. H. D. Rozman, R. N. Kumar, H. P. S. Khalil, A. Abusamah, and R. Abu, European Poly. J. 33 (8), 1213 (1997). doi:10.1016/S0014-3057(97)00008-6

25. H. D. Rozman, R. N. Kumar, A. Abusamah, and M. J. Saad, J. App. Poly. Sci. 67, 1224 (1998). 